\title{
Chapter
}

\section{Semaphorin Signals in Cell Adhesion and Cell Migration: Functional Role and Molecular Mechanisms}

\author{
Andrea Casazza, Pietro Fazzari and Luca Tamagnone*
}

\begin{abstract}
ell migration is pivotal in embryo development and in the adult. During development, a wide range of progenitor cells travel over long distances before undergoing terminal differentiation. Moreover, the morphogenesis of epithelial tissues and of the cardio-vascular system involves remodelling compact cell layers and the sprouting of new tubular branches. In the adult, cell migration is essential for the leucocytes involved in immune response. Furthermore, invasive and metastatic cancer cells have the distinctive ability to overcome normal tissue boundaries, travel in and out the blood vessels, and settle down in heterologous tissues. Cell migration normally follows strict guidance cues, either attractive, or inhibitory and repulsive. Semaphorins are a wide family of signals guiding cell migration during development and in the adult. Recent findings have established that semaphorin receptors, the plexins, govern cell migration by regulating integrin-based cell substrate adhesion and actin cytoskeleton dynamics, via specific monomeric GTPases. Plexins furthermore recruit tyrosine kinases in receptor complexes, which allows switching between multiple signalling pathways and functional outcomes. In this article, we will review the functional role of semaphorins in cell migration and the implicated molecular mechanisms controlling cell adhesion.
\end{abstract}

\section{Introduction}

Semaphorins were initially identified as evolutionarily conserved axonal guidance cues in the assembly of the neural circuitry. However, it is now clear that they form a collection of more than twenty soluble or membrane-bound molecular signals (in vertebrates), involved in a range of different processes that often implicate the regulation of cell-substrate adhesion and directional cell migration.

The receptors for semaphorins belong to a family of plasma membrane molecules, the Plexins. ${ }^{1}$ Two plexins are found in invertebrate genomes, whereas nine genes are known in humans. Interestingly, a common structural domain, known as the "sema domain", is present in the extracellular region of semaphorins, plexins and scatter factor receptors, which underlines the phylogenetic link between these gene families. ${ }^{2,3}$ It was recently shown that the structure of the sema domain is a so-called "beta-propeller", similar to that found in $\alpha$-integrins. ${ }^{4-6}$ In addition to the sema domain, the extracellular region of plexins, semaphorins and $\beta$-integrins contains cysteine-rich "PSI" domains, further underlining the structural similarity between

*Corresponding Author: Luca Tamagnone-Institute for Cancer Research and Treatment (IRCC), Str. Prov. 142, I-10060 Candiolo (Torino), Italy. Email: luca.tamagnone@ircc.it

Semaphorins: Receptor and Intracellular Signaling Mechanisms, edited by Jeroen Pasterkamp. (C)2006 Landes Bioscience. 
Table 1. Identified semaphorin receptors

\begin{tabular}{lll}
\hline & Semaphorin & Receptor(s) \\
\hline Secreted & Sema3A & Neuropilin-1 + Plexins (PlexinAs, PlexinDi) \\
& Sema3B & Neuropilin-1/Neuropilin-2 + Plexins? \\
& Sema3C & Neuropilin-1/Neuropilin-2 + Plexins (PlexinA2?) \\
& Sema3E & PlexinDi, Neuropilins? \\
& Sema3F & Neuropilin-2 + Plexins (PlexinA3) \\
Membranebound & Sema4A & TIM2 (low affinity) \\
& Sema4D & PlexinBi (PlexinB2), CD72 (low affinity) \\
& Sema5A & PlexinB3, Proteoglycans (via TSP repeats) \\
& Sema6A & PlexinA4 \\
& Sema6B & PlexinA4? \\
& Sema6D & PlexinAl \\
Sema7A & PlexinCi, Integrin-betal (affinity unknown) \\
& A39R & PlexinCi \\
\hline
\end{tabular}

semaphorin receptors and the integrin receptor complexes. The cytoplasmic domain of plexins, instead, lacks any striking homology to known proteins or functional motifs, but it contains two amino acid stretches weakly similar to GTPase Activating Proteins (GAPs), and it was recently shown to catalyse the inactivation of R-Ras monomeric GTPase. ' In addition to that, plexins are found in association with receptor- and nonreceptor-type tyrosine kinases. ${ }^{8}$

Many secreted class 3 semaphorins are unable to interact with plexins directly. Therefore the plexins form receptor complexes with the Neuropilins, which provide a high-affinity binding site for secreted semaphorins. ${ }^{1,9}$ Notably, neuropilins also interact with Vascular Endothelial Growth Factors (VEGFs) and with their tyrosine kinase receptors (VEGF-Rs). Although neuropilins carry a small conserved cytoplasmic tail, yet there are contradictory results on the signaling competence of this domain. According to many reports, neuropilins only provide a ligand-binding platform in the complex and the intracellular signaling is mediated by the associated plexins; other findings, however, suggest an independent signaling function of the intracellular domain of neuropilins. ${ }^{10}$ Intriguingly, certain semaphorins have been reported to interact with other receptors, in addition to plexins and neuropilins. An up to date index of the identified semaphorin receptors can be found in Table 1. Moreover, transmembrane semaphorins (subclasses 1, 4, 5 and 6) may signal in bi-directional manner, since they carry intracellular domains that can mediate the so called "reverse" signaling into expressing cells (in addition to the classical "forward" signaling elicited in cells expressing the receptors). ${ }^{11,12}$

\section{Functional Role of Semaphorins in Cell Adhesion and Cell Migration}

Initially, most studies on semaphorins focused on their repelling activity for extending axons. Subsequently, it was demonstrated that they regulate the migration of a variety of cells, including neuronal precursors, neural crest cells, oligodendocytes, endothelial cells, leucocytes, epithelial cells and tumor cells derived from carcinomas, melanomas, etc. ${ }^{8}$ As summarized in Table 2, several semaphorins can negatively regulate integrin function, cell adhesion and cell migration. However, semaphorin signaling is multifaceted, and a subset of these ligands (e.g., Sema4D, Sema6D and Sema7A) was furthermore shown to elicit integrin activation/ cell-substrate adhesion, axon outgrowth and cell chemotaxis in distinctive conditions (see Table 2). Although the molecular mechanisms responsible for these antagonistic activities have not been completely understood, they seem to implicate distinctive signaling pathways, depending on the targeted cells and on the different components of the semaphorin receptor complexes. ${ }^{8,13}$ 


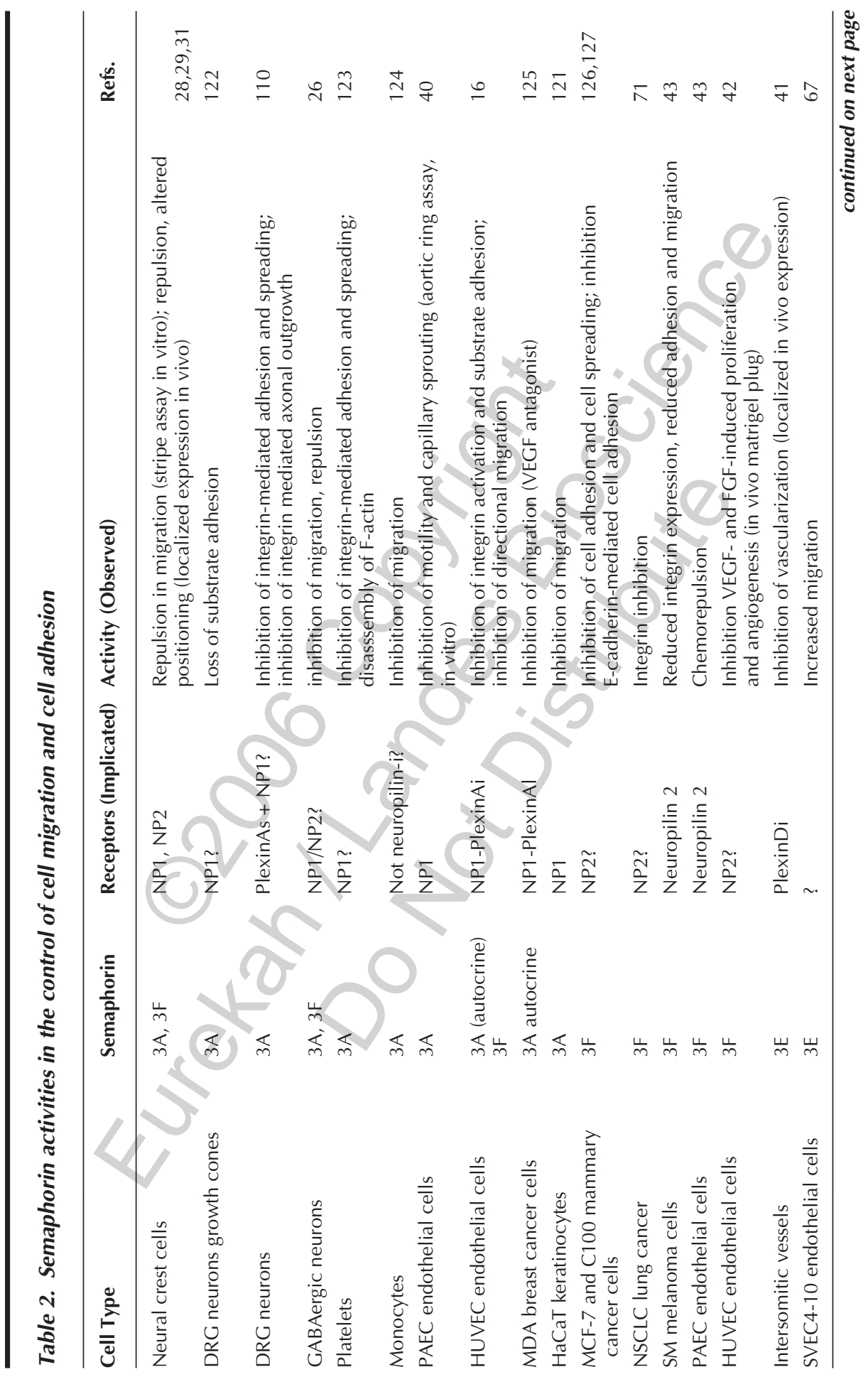




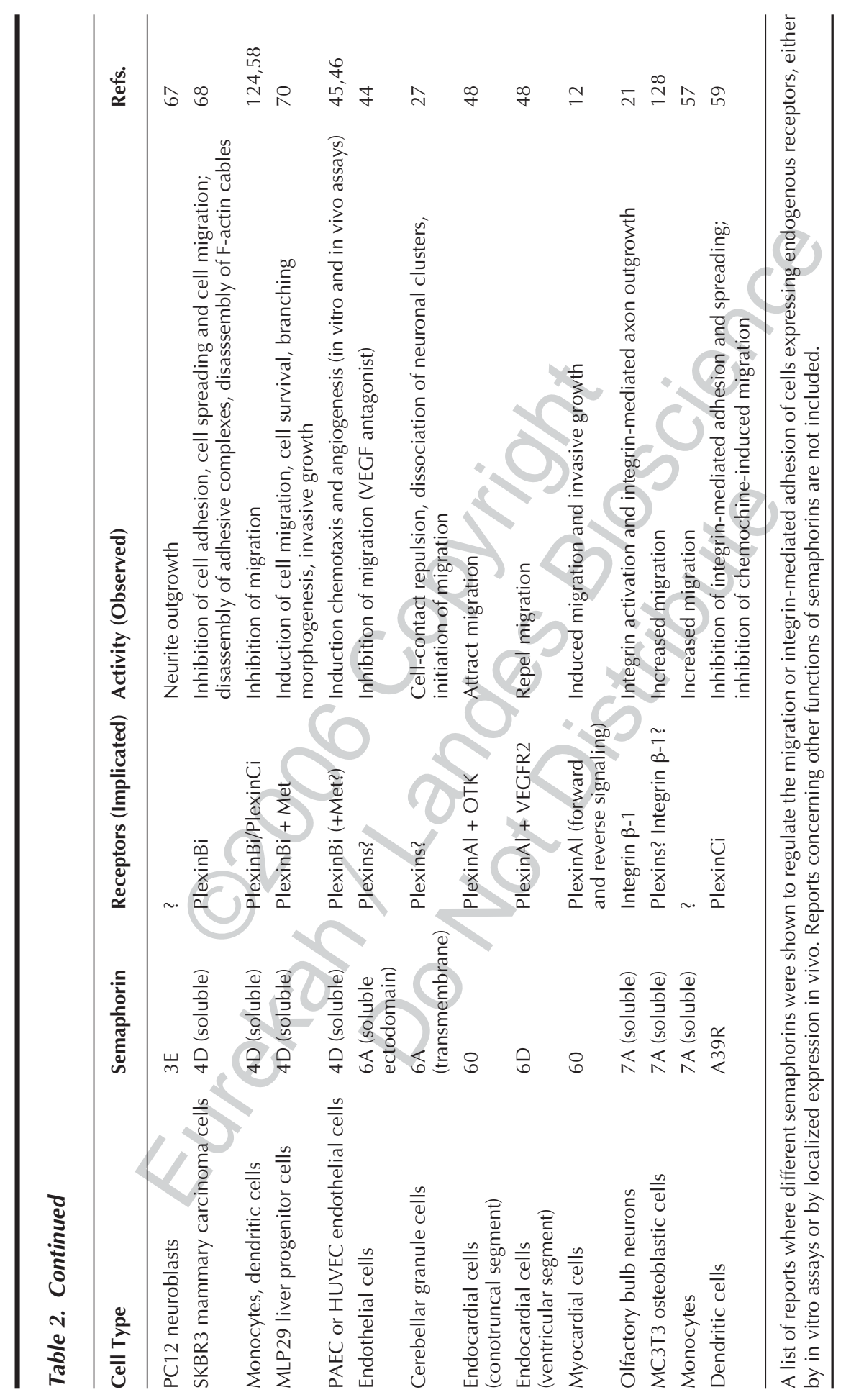




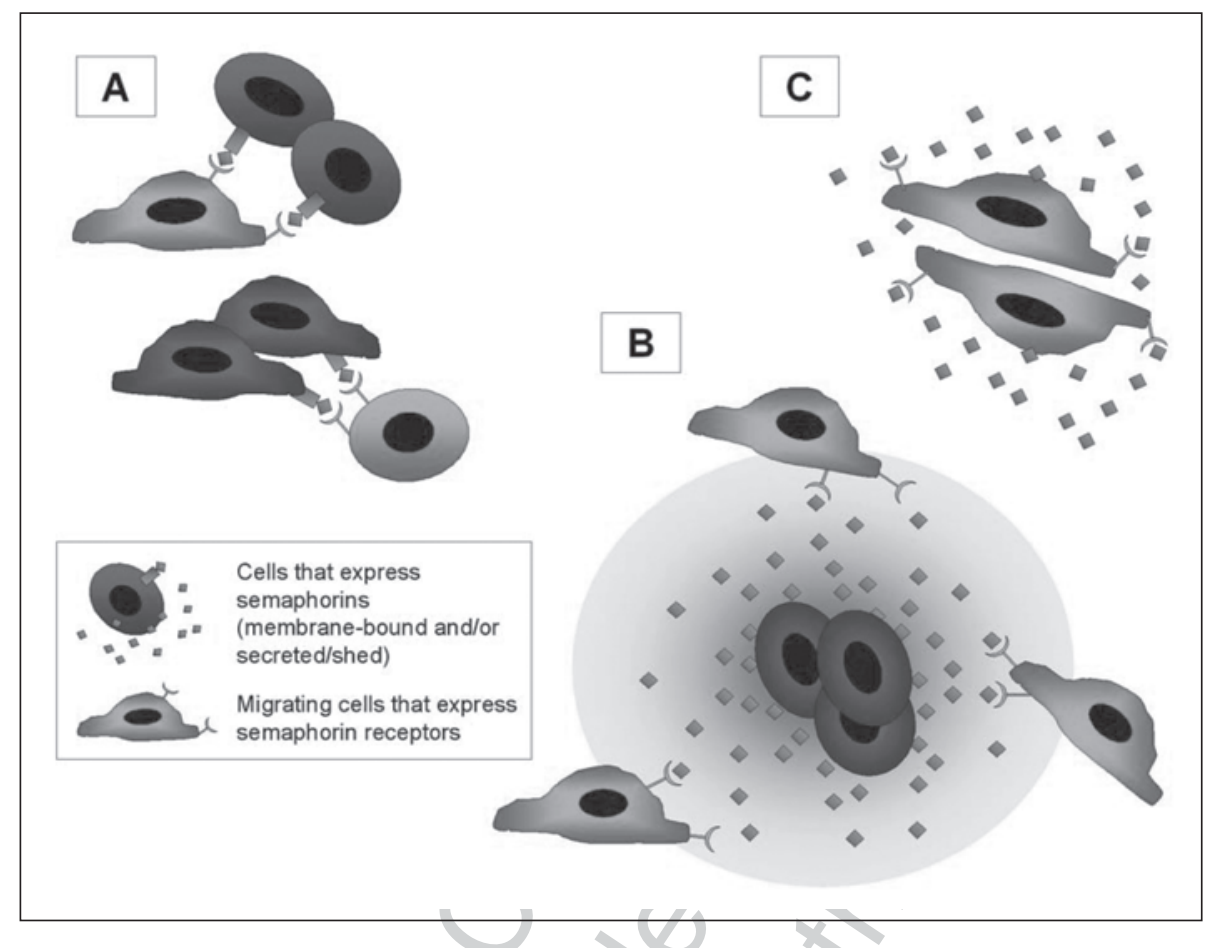

Figure 1. Semaphorin signals act in juxtacrine, paracrine and autocrine manner. A) Membrane-bound semaphorins expressed by guidepost cells can mediate localized signals to guide migration (e.g., Sema6D, Sema6A); B) secreted/shed molecules can diffuse in the area of expressing cells, and demarcate it as a "no entry" zone for cell populations expressing the specific receptors (e.g., Sema3A, Sema3F); C) migrating cells may establish autocrine loops of secreted/ shed semaphorins, to police their own migration (e.g., Sema3A).

As mentioned above, semaphorins include secreted and membrane-bound molecules. In addition, certain membrane-bound semaphorins (e.g., Sema4D) are proteolytically released ("shed") in the extracellular space in active form. ${ }^{14,15}$ Available data indicate that the control of cell migration by semaphorin signals follows three paradigms, illustrated in Figure 1: (A) membrane-bound semaphorins at the cell surface can mediate localized signals to guide migration; (B) secreted/shed molecules can diffuse in the area of expressing cells, and demarcate it as a "no entry" zone (or instead form a chemotactic gradient) for cell populations expressing the specific receptors; (C) migrating cells may establish autocrine loops of secreted/shed semaphorins, to police their own migration: e.g., it was found that the inactivation of autocrine Sema3A signaling in endothelial cells results in increased directional persistence. ${ }^{16}$

What are the molecular pathways underlying the control of cell adhesion and cell migration by semaphorins? It is known that integrin-mediated adhesion and cell migration are intimately linked processes, since the latter crucially depends on a dynamic regulation of cell tethers to the extracellular matrix (ECM); for a more general review on this topic, see reference 17 . Thus, migration must be considered a cyclic multistep process. Migrating cells continuously sense extracellular guidance cues at their polarized "leading edge". These signals, including the semaphorins, may either support further movement in a specific direction ("attractive" cues) or prevent it ("repelling" cues). In response to a repelling cue, the leading edge collapses and small protrusions test the environment, until the cell gets polarized towards a new "permissive" direction. Therefore, repelling cues not only define "off" territories where the migration of a specific 
cell is not allowed, but also serve to put directional migration "on hold", and reset the threshold for attractive signals. In contrast, when stable adhesive complexes are established, the cell body is pulled forward by cytoskeletal contraction; this results in cell translocation and restarts the extension cycle. It should be underlined that cell migration requires a dynamic regulation of cell-substrate adhesion; in fact, it is hampered both in the presence of stiff adhesive structures, and when integrin function is impaired and adhesive structures cannot form or cannot connect with the actin cytoskeleton. For long time, semaphorins have been shown to elicit depolymerization and remodeling of the actin cytoskeleton, thereby blocking leading edge extension and inducing lamellipodia retraction (often indicated as the "collapsing response"). Accumulating evidence now show that semaphorins can negatively regulate integrin function and cell-substrate adhesion. By this means, they can greatly affect cell and axon navigation, since the leading edge of a migrating cell (or an axon growth cone) is steered not only by "polarizing" attracting signals and "depolarizing" repelling signals, but also by changes in the "permissive" cues locally provided by the adhesive substrate.

We will now discuss the experimental data supporting the role of semaphorins in the regulation of cell adhesion and cell migration in vivo, whereas in the second part of the review we will sketch a picture of the signaling pathways currently implicated in these functions.

\section{Axon Guidance}

Semaphorins have a prominent role to wire the neural network by guiding axon pathfinding. Notably, the mechanisms controlling axonal extension share remarkable similarities with those acting in cell migration. In fact, at the tip of the axon, a specialized structure termed the growth cone explores the surrounding environment, via repeated cycles of protrusion and collapse. The mechanistic explanation of this process classically focused on the regulation of cytoskeletal dynamics. However, it is well known that integrin-mediated adhesion does play a role in axon guidance, and guidance cues may regulate the affinity of axons to ECM components; ${ }^{18,19}$ for a review see reference 20 . Nonetheless, direct links between semaphorins and integrins during axon guidance were provided only recently. By a series of elegant experiments in vitro and in vivo, Pasterkamp and colleagues showed that the GPI-linked Sema7A is necessary to promote axon outgrowth from the olfactory bulb. ${ }^{21}$ In this model, Sema7A elicits the activation of integrin- $\beta 1$ and promotes axon outgrowth via MAPK activation downstream to integrin signaling. In principle, semaphorins known to inhibit integrin activation, such as Sema3A and Sema3F, may act in an opposite manner: thereby preventing integrin activation and growth cone adhesion in areas from where the axon is steered away. Direct evidence of this mechanism, however, is currently missing.

An intriguing insight into the connection between semaphorins and integrin-mediated adhesion in axon guidance emerges from the functional role of Sema3B in the formation of the anterior commisure (AC). This is a bipartite tract formed by an anterior $(\mathrm{ACa})$ and a posterior (ACp) limb that converge into a common fascicle during development. Sema3B exerts a dual function on these axons: being attractive for $\mathrm{ACa}$ and repulsive for Acp. ${ }^{22}$ Although the implicated mechanisms are not fully understood, it was found that FAK, a Src-like tyrosine kinase associated with integrin-based focal adhesions, is recruited to the membrane and gets phosphorylated only in ACa neurons (those attracted by the semaphorin). Furthermore, the pharmacological inhibition of Src, likely implicated in FAK activation, converts the attractive response of ACa neurons into repulsion. ${ }^{22}$

During development, axonal growth cones are eventually guided by specific signals to connect with target cells and form synapses, later to be remodeled in the adult. Pre and postsynaptic membranes are actually linked by cell junctions, similar to those found between epithelial cells and between immune-response cells (the "immunological synapse"). A role for Semaphorins in the formation and plasticity of synapses was initially proposed in Drosophila, where both secreted Sema 2 and the transmembrane Semala were found to regulate synaptogenesis, through different mechanisms. ${ }^{11,23}$ In mammals, during hippocampal development, exuberant synap- 
tic connections are normally eliminated, followed by the retraction of redundant "nonconnected" axons. Noteworthy, in mice lacking PlexinA3 or NP2, the pruning of unnecessary synapses and axon collaterals is impaired. ${ }^{24}$ Therefore, semaphorins not only act as topographical guiding cues, but can also provide temporally-restricted signals controlling the stability of cell-cell contacts, for instance in synaptic plasticity. Intriguingly, since the expression of many semaphorins is maintained in the adult nervous system, these findings could pave the way for studying the potential role of semaphorin signaling in synaptic plasticity disorders.

\section{Neuronal Migration}

During the development of the central nervous system (CNS), cell migration is a fundamental process, since neurons and glial cell usually originate in proliferative zones that are far from the sites where they will ultimately reside. The role of the semaphorins in the control of this migratory process is currently emerging.

Most of the neurons migrate radially, using "radial glia" as a track, and the regulation of this process is believed to be essentially contact-mediated. A significant population of GABAergic neurons, instead, arises in the ventricular zone of the subpallium and undergoes tangential migration. While a small fraction of these cells is then sorted to the striatum, the majority avoids this region, ending their journey in the piriform cortex and the neocortex. In vivo and ex vivo experiments ${ }^{25,26}$ showed that the striatum expresses Sema3A and Sema3F. The neurons avoiding this area express both neuropilin- 1 and -2 , while those invading the striatum do not express any competent semaphorin receptors. In fact, loss of neuropilin function hijacks the control of migration into the striatum, thus increasing the number of neurons entering this area and reducing the number of those migrating to the cortex. ${ }^{25}$ In sum, neuropilin expression segregate different subpopulations of GABAergic neurons, and semaphorin signaling is required for their sorting toward specific locations.

Another example of semaphorins controlling neuronal migration is found in cerebellar development. Here granule cells proliferate after birth in the external granular layer (EGL), from where they start an inward radial migration, through the molecular layer (ML) and on the "track" of Bergmann glia, into the internal granule layer (IGL). The role of transmembrane semaphorin Sema6A in this process was recently demonstrated by gene-ablation experiments, providing a fascinating example of the fine-tuned clockwork of neural development. ${ }^{27}$ In Sema6A-deficient mice, the inward migration of granule cells is impaired as many of them remain ectopic in the ML (where they differentiate and connect with the mossy fibers). An extensive analysis of these mutants revealed that, surprisingly, granule cell development is otherwise completely normal (e.g., concerning proliferation, differentiation, survival and even neurite extension). The authors suggest a model in which Sema6A acts as cell-cell contact repellent, providing the cell body of granule cells with a "go" signal to leave the EGL and start the inward radial migration. Notably Sema6A expression in granule cells is turned off as soon as they leave the EGL.

\section{Neural Crest Cell Migration}

Neural crest cells originate in the dorsal region of the neural tube and migrate out to peripheral districts. They are in fact the precursors of a remarkable assortment of differentiated cell types, including pigment cells (melanocytes), skeletal cartilage cells (chondroblasts), cells "patterning" heart development, autonomic ganglion cells, and glial cells of the peripheral nervous system. The analysis of these cells in vitro provided one of the first examples that semaphorins can regulate cell migration, beyond axon guidance. ${ }^{28}$ Studies in chicken embryo have later revealed that neural crest cells in the hindbrain and in the trunk express neuropilin receptors, and are selectively excluded from those regions containing Sema3A and Sema3F. ${ }^{29}$ Moreover, ectopic expression of Sema3A or Sema3F in vivo (or expression of soluble neuropilins as decoy receptors) results in the disruption of the normal "streams" of migrating cells. These findings are consistent with loss-of-function experiments in mice. In fact, both Sema3A and NP1 
knock-out animals display defects in the migration of neural crest cells of the sympathetic lineage, leading to the mislocalization of mature sympathetic neurons and to an impaired development of sympathetic ganglia. ${ }^{30}$ Similar functions were recently reported for Sema3F in mouse and in zebrafish development. ${ }^{31,32}$ In addition, in experiments on explanted sympathetic ganglia, Sema3A, possibly due to its repelling activity, promoted cell aggregation and tight neurite fasciculation. ${ }^{30}$ Notably, a subset of migrating neural crest cells characterized by the expression of PlexinA2 is crucially implicated in cardiac development, on guidance by secreted semaphorins ${ }^{33,34}$ (see below).

\section{Oligodendrocyte Migration}

As mentioned above, cell guidance is fundamental for migrating glial precursors too. Although little is known about the specific cues controlling this process, it is assumed that some of them may be common to axon pathfinding and neuronal cell migration. In fact, there is evidence indicating a potential role of different semaphorins in oligodendrocyte migration. ${ }^{35}$ Moreover, it was reported that oligodendrocyte precursors recruited to the optic nerve express both neuropilin-1 and -2; interestingly, a subpopulation of these cells is repelled by Sema3A, whereas Sema3F acts as chemoattractant and mitogenic factor. ${ }^{36}$ Other reports indicated a specific expression of transmembrane semaphorins Sema5A and Sema4D in oligodendrocytes, suggesting their role to regulate axon pathfinding, myelination and nerve regeneration. ${ }^{37,38}$

\section{Angiogenesis}

There is consistent evidence that semaphorin signals regulate endothelial cell migration and angiogenesis (for details, see an associated review by Neufeld and coworkers in ref. 39). Sema3A was shown to inhibit both the adhesion of endothelial cells to the extracellular matrix and their directional migration. ${ }^{16,40}$ Moreover, Sema3A- and Sema3E-deficient mice display defects in vascular development, ${ }^{16,41}$ and Sema3F and Sema6A were shown to act as anti-angiogenic factors in experimental tumors. ${ }^{42-44}$ On the other hand, Sema4D (and other members of subclass 4) were consistently reported to have pro-angiogenic activity in vitro and in vivo. ${ }^{45,46}$

\section{Organ Morphogenesis}

The role of Sema3A, Sema3C and Sema6D in cardiac development is well documented in vivo by gene-loss experiments. Secreted semaphorins Sema3A and Sema3C regulate the migration of neural crest cells that play a crucial role in shaping the heart and the aortic outflow in mice. ${ }^{33,34,47}$ In chick, Sema6D signaling was found to affect the organogenesis of both the ventricle and the cardiac outflow tract. Interestingly, the transmembrane semaphorin Sema6D acts bidirectionally: by forward signaling via PlexinA1, and by "reverse" signaling, via the association of Abl-regulatory proteins to its cytoplasmic tail. ${ }^{12,13,48}$ Moreover, forward signals mediated by Sema6D-PlexinA1 interaction can either be attractive or repelling in different cell populations, depending on the receptor tyrosine kinase associated with the plexin, i.e., VEGFR2 or OTK, respectively. On the other hand, "reverse" signals elicited into Sema6D-expressing cells seem to promote invasive growth. For more details on this topic, see reference 49.

The morphogenetic role of semaphorins has also been extensively addressed in lung development. Moreover, lung development may provide a general example of tubulogenesis and branching morphogenesis, as observed in other organs (e.g., kidney, pancreas etc.). This process begins from a simple epithelial sheet that ends up as a branched tubular structure. Notably, the remodelling of epithelial layers somewhat parallels the migration process of a single cell, since the entire cluster trails the movements of the cells at the leading edge, sensing the environmental guidance cues. In analogy to neural development, we speculate that semaphorins act by defining permissive and restrictive regions during branching morphogenesis, to carve the shape of the epithelial tree. In fact, at the early stage of lung organogenesis (embryonic days 11-13) Sema3A is expressed in the distal mesenchyme, while neuropilins are found in the 
epithelium of terminal buds. It was shown in organotypic cultures that Sema3A inhibits the branching of lung epithelium, while Sema3C and Sema3F increase the branching and slightly promote epithelial cell proliferation. ${ }^{50,51}$ These data support a model in which the differential distribution of semaphorins, in concert with that of growth factors and other morphogenetic cues, coordinates the shaping of lung epithelial tree.

Numerous reports have indicated a developmental role of semaphorin signals to prevent ectopic cell contacts during epidermal morphogenesis in the nematode C.elegans; in particular, semaphorins are implicated in the sorting of cells into distinct rays of the developing male tail. $^{52-54}$ Moreover, although the interpretation of the morphogenetic process differs, two recent reports have established a role of Sema1a/PlexinA signaling to regulate the developmental migration of vulval precursor cells in the same organism. ${ }^{55}$

\section{Leucocyte Migration}

Scattered reports have shown that semaphorins can affect leucocyte migration, as assayed by in vitro migration assays. ${ }^{57-59}$ However, functional in vivo evidence of this activity is still lacking. On the other hand, knock-out mouse models generated in H. Kikutani's lab have clearly demonstrated that class 4 semaphorins Sema4D and Sema4A regulate the immune response mediated by lymphocytes and dendritic cells. ${ }^{60,61}$ Interestingly, PlexinA1 was shown to have a role in the "adhesion" between lymphocytes and regulatory cells ${ }^{62}$ (the so called "immunological synapse"), inviting the idea that semaphorins could police this association. This matter is reviewed in detail in an associated review. 63

\section{Tumor Cell Migration}

Tumor cell migration is a fundamental process in cancer progression, as it sustains local invasion and metastatic dissemination. Notably, it depends not only on the activity of motogenic factors and guidance cues, but also on mechanisms dissolving the extracellular matrix and inhibiting tumor cell apoptosis. Several scattered reports have indicated an altered expression of semaphorins in cancer (inter alia see refs. 64,65). Experimental evidence in vitro and in vivo supported these data, suggesting that semaphorin signaling can act to promote or to inhibit cancer progression, depending on the receptor complex involved. ${ }^{42-44,66,67}$ One interesting example is Sema4D, which was shown to inhibit the migration of carcinoma cells expressing the receptor PlexinB1, ${ }^{68}$ while it sustains the constitutive activation of the oncogenic receptor Met (associated with the plexin) in other cells. ${ }^{69,70}$ Noteworthy, semaphorins found to inhibit the migration of tumor cells, also affect integrin-dependent adhesion or integrin expression. ${ }^{43,68,71}$ The effect of tumor-produced semaphorins in vivo is further explained by an interference with cancer-associated angiogenesis. ${ }^{42-44}$ For a detailed review of this exciting field of ongoing research, see reference 39 .

\section{Signaling Molecules Mediating Semaphorin Function in Cell Adhesion and Migration}

The cytoplasmic domain of plexins, or SP domain, is split into two highly conserved regions, separated by a "linker domain" with more divergent sequence. ${ }^{72}$ This domain lacks any striking homology to known proteins or functional motifs; however it includes short sequences with similarity to GTPase activating proteins ${ }^{73}$ (or GAPs), and it was recently shown to mediate GAP activity for R-Ras, leading to the inactivation of this small GTPase. ${ }^{7}$ Figure 2 shows many intracellular signal transducers that have been implicated in plexin-mediated functions, some of which interact directly with the SP cytoplasmic domain. ${ }^{74}$ However, it remains largely unclear how these different pathways connect to mediate functional responses to semaphorins. In this review, we will focus on those molecules known to have a role in the control of cell adhesion and cell migration. 


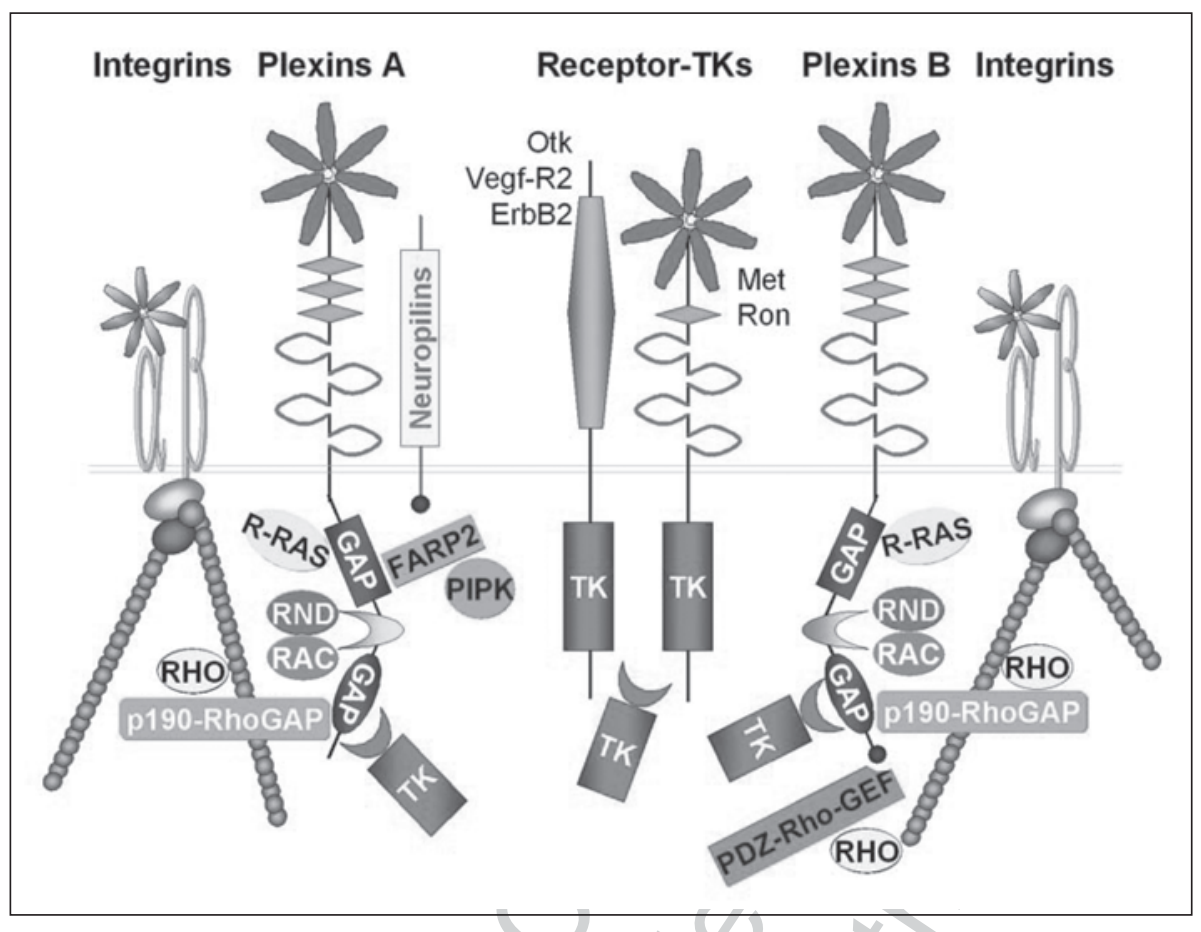

Figure 2. Plexins associate a range of signal transducers implicated in the control of integrin function and cytoskeletal dynamics. The figure schematically depicts most of the players implicated in the control of cell adhesion and cell migration mediated by semaphorins (see the text for details). Plexins and Receptor Tyrosine Kinases of the Met family share a common structural domain known as the "sema domain" (shown in red), whose structure is a "beta-propeller", similar to that found in $\alpha$-integrins. In addition to the sema domain, the extracellular region of plexins contains two/three PSI domains (found in Plexins, Semaphorins and $\beta$-Integrins; shown in green) and three/four IPT domains (Ig-like, Plexins, Transcription factors; shown in blue), which are putative protein-protein interaction motifs. The cytoplasmic domain of plexins contains two conserved regions with intrinsic R-Ras-GAP activity (depicted in blue), and a linker segment more variable in the family, which interacts with other small GTPases (shown in yellow). The cytoplasmic domain of plexins furthermore interacts with p190-RhoGAP, controlling the actin cytoskeleton, and with FARP2, which sequesters and inactivate PIPKIgamma (resulting in the destabilization of cell adhesive complexes). At the C-terminus of the plexins of B subfamily there is a consensus sequence for PDZ domains, which mediates the selective association with PDZ-RhoGEFs (see the text for details).

\section{Monomeric G Proteins as Main Regulatory Switches for Plexin Signaling}

Monomeric GTPases of the Rho and Ras family are pivotal regulators of intracellular cell signaling. Through their activity, specific signals from the extracellular microenvironment may be rapidly translated into cytoskeletal remodeling events, such as those regulating cell adhesion and cell migration. It is therefore not surprising that these molecules play a pivotal role in semaphorin signaling (for more details see ref. 75).

It was demonstrated that the cytoplasmic domain of Plexins directly associates with GTPases of the Rho family and with their regulatory proteins. For instance, activated GTP-bound Rac1 was found to interact directly with the cytoplasmic domain of PlexinB1 and PlexinA1. ${ }^{76-78}$ However, plexins were not found to mediate GAP activity for Rac. Moreover, previous reports 
showed that both the expression of dominant negative $\mathrm{Rac}^{79,80}$ and the treatment with an inhibitory peptide for $\mathrm{Rac}^{81}$ block Sema3A-induced neuron growth cone collapse, indicating the requirement for Rac activation in plexin signaling. Therefore, in the effort to explain its functional role, this interaction was proposed to: (1) direct the localization of active Rac to the cell membrane, where it could regulate cytoskeletal remodeling and protein trafficking; ${ }^{82}$ (2) locally sequester the active form of the GTPase from its downstream targets, such as PAK1, thereby inhibiting Rac signaling at the cell membrane; ${ }^{83,84}$ (3) mediate a conformational change in the cytoplasmic domain of the plexin, regulating its signaling activity or further interactions with other cytoplasmic proteins; ${ }^{78}$ (4) control the targeting of plexin molecules at the cell surface. $^{84,85}$

Independent reports showed that another GTPase of the Rho family, Rnd-1, which is constantly loaded with GTP due to low intrinsic GAP activity, can associate with the same region of the intracellular domain of Plexins as Rac. ${ }^{86,87}$ However, similar to Rac, plexins do not carry any GAP activity to inactivate Rnd1. Instead, the association of this GTPase to the cytoplasmic domain of plexins seems to act as a switch, to allow for further interaction with other transducers, such as R-Ras or GTP/GDP exchanger proteins (or GEFs) for RhoA. ${ }^{7,87}$ Notably, mutations in the primary sequence of this GTPase-binding region of plexins also affect cell surface expression of the receptor, by unknown mechanisms. ${ }^{85}$ In conclusion, the interaction with Rac1 and Rnd 1 seems to play a major regulatory role upstream to plexin signaling, by policing receptor activation and interaction with intracellular transducer molecules.

Further extracellular and intracellular mechanisms have been reported to provide regulatory switches for plexin signaling. For example Ig-like cell adhesion molecules (such as L1-CAM or $\mathrm{Nr}-\mathrm{CAM}$ ) associate with neuropilins and may differentially regulate certain semaphorin receptor complexes, depending on cell-contact-mediated homophilic interactions with neighbor cells. ${ }^{88}$ Other intriguing findings implicate that the differential expression of proteoglycans in diverse areas of the nervous system may assign either attractive or repelling function to Sema5A signals. ${ }^{89}$ Furthermore, at the intracellular level, it was shown that the balance between cyclic nucleotides cAMP and cGMP may switch Sema3A signaling from repulsion to attraction. ${ }^{90}$

\section{Integrins and the Actin Cytoskeleton Are Major Targets of Plexin Signaling}

Several reports showed that plexin signaling primarily regulates integrin function. In most instances, semaphorin stimulation leads to: decreased cell-substrate adhesion, decreased integrin expression, block of integrin activation or transition of integrins in the inactive state, disassembly of integrin-based cell adhesion complexes, actin cytoskeleton remodeling with loss of stress fibers, and morphological rearrangements such as retraction of cell protrusions and cell rounding (see Table 2). In addition, loss of integrin activation (and of the associated "outside-in" signaling) may explain other functional effects induced by semaphorins, such as reduced proliferation rate and cellular apoptosis. In certain instances, however, semaphorins were reported to regulate integrin function in the opposite manner: for example, Sema7A stimulation induces the activation of $\beta$-integrins and of their associated intracellular pathway, including FAK and MAPK. ${ }^{21}$

The molecular mechanisms of integrin regulation by semaphorins are partly understood. At present, a compelling evidence that semaphorins or their receptors can directly interact with integrins is missing. However, plexins carry an intrinsic GAP activity for active R-Ras, a monomeric GTPase known to induce integrin activation. ${ }^{7}$ Notably, two conserved arginine residues are essential for R-Ras inactivation by plexins, and their point mutation results in the loss of most (although not all) functional responses mediated by plexins. ${ }^{68,73,91} \mathrm{R}-\mathrm{R}$ as is a major positive regulator of integrin function: ${ }^{92}$ it gets activated upon cell contact to the ECM, ${ }^{93}$ and in turn it sustains the clustering and activation of $\beta 1$-integrin receptors (as well as others), it enhances focal adhesion formation and cell adhesion, and it regulates positively cell spreading, cell migration and invasion, as well as axon outgrowth (for a general review see ref. 94). These 
functions qualify R-Ras as the ideal target for the inhibitory activity of semaphorins; nonetheless the molecular mechanisms involved in this pathway are presently unclear. Phosphatidylinositol-3 kinase (PI3K) and its main product PIP3 have been initially implicated as major effectors of R-Ras, ${ }^{95,96}$ to elicit the recruitment at the cell membrane of exchange factors activating Rac1, thereby promoting integrin-mediated adhesion. However, two recent reports demonstrated that R-Ras signaling instead induces RhoA activation and Rac1 inactivation at the leading edge, via still unknown pathways. ${ }^{93,97}$ Therefore, further studies are required to elucidate the mechanism whereby R-Ras inactivation mediated by semaphorins may regulate cell adhesion and cell migration.

Interestingly, other findings indicate that RhoA regulation is fundamental in plexin signaling. For instance, p190RhoGAP, the major negative regulator of RhoA at the leading edge, ${ }^{98}$ was recently shown to associate with plexins and become activated upon semaphorin binding. ${ }^{99}$ Moreover, in p190-deficient cells, plexin signaling was abrogated or significantly hindered. ${ }^{99}$ The regulatory function of RhoA in cytoskeletal remodelling, cell adhesion and cell migration is rather complex and multifaceted. ${ }^{100,101}$ During cell migration, the levels of active RhoA are highly dynamic: they are cyclically downregulated at the leading edge to disassemble the actin cytoskeleton and release cell-substrate adhesions, and this is transiently required to form cell protrusions. However, once lamellipodia establish new integrin-mediated contacts, RhoA becomes activated and elicits the formation of thick actin cables connected to the adhesive complexes, whose contraction is the "pulling" force in cell body translocation. Therefore, RhoA inactivation mediated by plexins inhibits acto-myosin contractility, disassembles actin cables and leads to weak and unstable adhesive complexes, which in turn blocks directional migration. ${ }^{68}$ Moreover, activated p190 is known to recruit to the complex p120-RasGAP, a general downregulator of Ras-like GTPases, including R-Ras; ${ }^{94}$ this could provide an additional mechanism to mediate R-Ras inactivation upon plexin signaling, and perhaps a functional link between the two pathways. Noteworthy, since data suggest that semaphorin signalling requires the regulation of both $\mathrm{R}$-Ras and RhoA, further investigation is needed to establish the specific role of these GTPases in different functional responses in vivo. For instance, recent findings indicate that R-Ras expression in vivo is mostly confined to blood vessels, ${ }^{102}$ which could underline a predominant role of this pathway in semaphorin-mediated control of angiogenesis.

It was also shown by many groups that Plexins of the B subfamily can associate with a subfamily of RhoA GTP/GDP exchangers (PDZ-RhoGEFs), via a unique and conserved C-terminal sequence that is not found in other plexins. ${ }^{103-107}$ This interaction is not influenced by the ligand, but depends on the association of Rnd 1 to the plexin ${ }^{87}$ and on the activity of ErbB2 tyrosine kinase recruited in the complex. ${ }^{108}$ Therefore, in certain instances, the activation of plexins B can induce RhoA activation, which is likely to be involved in specific functional responses mediated by plexins of the $\mathrm{B}$ subfamily, such as the pro-angiogenic activity of Semaphorin 4D. ${ }^{45}$ Plexin-associated RhoGEFs may furthermore be important in axon retraction, as demonstrated by expressing dominant negative forms of the RhoGEF or inhibiting Rho-dependent kinase (ROCK) in neurons. ${ }^{106}$ Moreover, genetic evidence in Drosophila showed that plexin signalling in axon guidance implicates Rho activation. ${ }^{83}$ Intriguingly, PDZ-RhoGEFs associated with plexins $B$ are multi-domain proteins that could provide a selective platform for the interaction with additional independent signaling pathways. ${ }^{109}$

Recent data highlighted the role of FARP2 (a FERM domain protein) to mediate Sema3A-mediated integrin inhibition in neurons derived from dorsal root sensory ganglia (DRG). ${ }^{110}$ Moreover, in FARP2-depleted neurons, Sema3A-mediated repulsion of neurite outgrowth is suppressed. Noteworthy, FARP2 was found to interact with plexins of the A subfamily, but not with PlexinB1. This molecule is likely to act by suppressing the kinase activity of Phosphatidylinositol-4-Phosphate 5-Kinase Type I $\gamma\left(\mathrm{PIPK}-\gamma_{661}\right)$, which is associated with integrin-based adhesive complexes. Intriguingly, a previous report indicated that Sema3A-mediated neurite retraction requires instead the activity of another isoform of PIPK, 
called PIPK-I $\alpha .{ }^{111}$ Although not localized to focal contacts, PIPK-I $\alpha$ activity was shown to induce vinculin dissociation from the adhesive complexes and release substrate adhesion. ${ }^{111}$ Therefore, the regulation of PIP2 levels at the cell surface seems to be an important mechanism to account for semaphorin-mediated control of cell-substrate adhesion and actin remodelling.

\section{Plexins and Tyrosine Kinases: Receptor Complexes That Can Make the Difference}

Tyrosine phosphorylation is another major regulatory mechanism implicated in cell adhesion and cell migration. Plexins do not carry an intrinsic kinase activity, however they can trigger the activation of plexin-associated receptor-type and nonreceptor-type tyrosine kinases (for a recent review, also see ref. 112). For example, PlexinB1 was found in complex with the receptor-tyrosine kinases Met, Ron and ErbB2. ${ }^{69,70,108}$ Upon semaphorin binding, the latter become activated, and in turn they phosphorylated plexins on tyrosine residues. The functional role of these interactions is currently under investigation: they could play a regulatory role on the cytoplasmic domain of plexins, but also trigger independent motogenic and survival pathways such as those mediated by Rac1 and RhoA, PI3K-AKT, FAK/MAPK, etc. This may also explain the bifunctional activity of Sema4D, which can either inhibit or promote cell adhesion and cell migration, depending on the activation of the associated Met kinase. ${ }^{69,113}$

Another interesting example is PlexinA1, which was found in complex with either VEGFR2 or the catalytic-inactive tyrosine kinase receptor Otk, in different cell populations. ${ }^{48}$ Upon binding Sema6D, this plexin elicts alternative signaling pathways in different cells: those expressing Otk were repelled by the semaphorin, while those expressing VEGFR2 were attracted. Notably, Otk is an orphan receptor kinase whose functional role in semaphorin signaling seems to be conserved from invertebrates to humans. ${ }^{114}$ In sum, the association with different kinase partners could explain the switch between different functions mediated by semaphorins, by eliciting independent transduction cascades.

Several nonreceptor-type tyrosine kinases have been implicated in semaphorin signaling, many of which can be found in focal adhesive complexes (e.g., Fyn, FAK, PYK2 and Src). In particular, Gutkind and coworkers have demonstrated that - upon Sema4D stimulation-the specific receptor PlexinB1 recruits PYK2 and Src cytosolic tyrosine kinases, eventually leading to the activation of $\mathrm{p} 110-\mathrm{PI} 3 \mathrm{~K}$ and of its downstream pathway. ${ }^{91}$ Notably, this pathway is independent of the ability to inactivate R-Ras and it is antagonistic to that reported in response to Sema3F. ${ }^{115}$ Moreover, there is evidence that it contributes to the chemotactic activity and pro-angiogenic function of Sema4D in endothelial cells. ${ }^{91}$

\section{Some Open Questions}

Semaphorins are known to trigger multiple signaling pathways, via plexins or alternative (poorly defined) mechanisms. Moreover, semaphorin stimulation may lead to different functional outcomes, depending on plexin-associated components in the receptor complex. A currently unanswered question is: how is regulated in cells the function of these semaphorin receptor complexes?

Although there is clear evidence that semaphorin signals regulate cell adhesion, it is almost completely unknown whether different integrin complexes are regulated by semaphorin receptors in the same manner. Could semaphorin signals elicit a differential adhesion to various ECM components found in tissues?

The functional link between regulation of integrin function and cell migration deserves further investigation. For instance, we speculate that the effects on cell migration elicited by semaphorins may depend on the grade of inhibition of integrin-mediated adhesion. Thereby, a limited release of cellular tethers to the ECM could actually be synergistic with motogenic signals.

The role of various small GTPases in semaphorin-mediated control of cell migration is less than clear, and some conflicting evidence have been obtained in different experimental models. 
Notably, certain "endpoint" functional responses in vitro, such as cell or growth cone collapse, may not reflect the dynamic nature of cell migration and axon guidance in vivo. Moreover, it is known that interfering with the levels of expression or activity of small GTPases may produce unpredictable basal effects. Thus, a more reliable analysis of the function of these molecules in plexin signaling would require the real-time detection of their sub-cellular localization and activation in living cells (e.g., by fluorescence-based techniques).

The membrane-bound or soluble nature of different semaphorins is often ignored in experimental studies, while this may be relevant to the function in vivo in several ways (localized "clustered" cues vs. diffused gradients, reverse signalling, etc.). Thus, new functional assays need to be developed to better address this issue in vitro.

Due to the seminal work of H. Fujisawa and collaborators, semaphorin receptors were originally described as homophilic/heterophilic cell adhesion molecules. ${ }^{116,117}$ Later reports confirmed this observation, ${ }^{62,118,119}$ suggesting the speculation that -by interfering with this function- semaphorins may regulate not only cell-substrate adhesion, but also cell-to-cell adhesion. Further analyses are thus required to test this hypothesis.

Finally, one intriguing aspect of semaphorin signaling in vivo is that independent cell types within a tissue may express receptors for the same semaphorin, leading to a complex scenario of integrated functional responses. For example, it is now clear that the development of neural and vascular networks share a range of guidance cues (including semaphorins, neurotrophins and VEGFs), which results in the coordinated arborization of vessels and neurites (for a review see ref. 120). Moreover, it is intriguing to note that semaphorins in tumors may exert a double functional role in cancer cells and in tumor-associated stroma. Future studies will tell how signals mediated by semaphorins are functionally integrated in different tissues, during development and in the adult.

\section{Conclusions}

Semaphorin signaling is now recognized as a major guidance code for axon pathfinding and cell migration. These activities underlie the functional relevance of semaphorins and their receptors in complex developmental processes, such as the wiring of the neural network, the migration of neural crest cells involyed in organogenesis, and the patterning of the vascular network. Furthermore, in the adult, the expression of semaphorins is maintained, and these signals are suspected to have an important role in neural plasticity and regeneration, in the immune function, and in cancer progression. Recent findings have established that the regulation of integrin-mediated adhesion is an important outcome of semaphorin signals, which may well account for their activities in axon guidance and cell migration. The molecular mechanisms linking semaphorins to integrins now begin to be understood; however further studies will be required to dissect the multiple intracellular pathways elicited by these signals.

\section{Acknowledgements}

We wish to thank Silvia Giordano, Livio Trusolino and Asha Balakrishnan for critical reading of the manuscript. For the financial support to their research activity, the authors wish to thank the Italian Association for Cancer Research (AIRC) and the Regione Piemonte.

\section{References}

1. Tamagnone L, Artigiani S, Chen $\mathrm{H}$ et al. Plexins are a large family of receptors for transmembrane, secreted, and GPI-anchored semaphorins in vertebrates. Cell 1999; 99(1):71-80.

2. Artigiani S, Comoglio PM, Tamagnone L. Plexins, semaphorins, and scatter factor receptors: a common root for cell guidance signals? IUBMB Life 1999; 48(5):477-482.

3. Winberg ML, Noordermeer JN, Tamagnone L et al. Plexin A is a neuronal semaphorin receptor that controls axon guidance. Cell 1998; 95(7):903-916.

4. Antipenko A, Himanen JP, van Leyen K et al. Structure of the semaphorin-3A receptor binding module. Neuron 2003; 39(4):589-598.

5. Love CA, Harlos K, Mavaddat $\mathrm{N}$ et al. The ligand-binding face of the semaphorins revealed by the high-resolution crystal structure of SEMA4D. Nat Struct Biol 2003; 10(10):843-848. 
6. Gherardi E, Youles ME, Miguel RN et al. Functional map and domain structure of MET, the product of the c-met protooncogene and receptor for hepatocyte growth factor/scatter factor. Proc Natl Acad Sci USA 2003; 100(21):12039-12044.

7. Oinuma I, Ishikawa Y, Katoh H et al. The Semaphorin 4D receptor Plexin-B1 is a GTPase activating protein for R-Ras. Science 2004; 305(5685):862-865.

8. Tamagnone L, Comoglio PM. To move or not to move? Semaphorin signalling in cell migration. EMBO Rep 2004; 5(4):356-361.

9. Takahashi T, Fournier A, Nakamura F et al. Plexin-neuropilin-1 complexes form functional semaphorin-3A receptors. Cell 1999; 99(1):59-69.

10. Wang L, Zeng H, Wang P et al. Neuropilin-1-mediated vascular permeability factor/vascular endothelial growth factor-dependent endothelial cell migration. J Biol Chem 2003; 278(49):48848-48860.

11. Godenschwege TA, Hu H, Shan-Crofts X et al. Bi-directional signaling by Semaphorin 1a during central synapse formation in Drosophila. Nat Neurosci 2002; 5(12):1294-1301.

12. Toyofuku T, Zhang H, Kumanogoh A et al. Guidance of myocardial patterning in cardiac development by Sema6D reverse signalling. Nat Cell Biol 2004; 6(12):1204-1211.

13. Comoglio PM, Tamagnone L, Giordano S. Invasive growth: a two-way street for semaphorin signalling. Nat Cell Biol 2004; 6(12):1155-1157.

14. Elhabazi A, Delaire S, Bensussan A et al. Biological activity of soluble CD100. I. The extracellular region of CD100 is released from the surface of T lymphocytes by regulated proteolysis. J Immunol 2001; 166(7):4341-4347.

15. Wang X, Kumanogoh A, Watanabe C et al. Functional soluble CD100/Sema4D released from activated lymphocytes: possible role in normal and pathologic immune responses. Blood 2001; 97(11):3498-3504.

16. Serini G, Valdembri D, Zanivan $S$ et al. Class 3 semaphorins control vascular morphogenesis by inhibiting integrin function. Nature 2003; 424(6947):391-397.

17. Ridley AJ, Schwartz MA, Burridge K et al. Cell migration: integrating signals from front to back. Science 2003; 302(5651):1704-1709.

18. Ivankovic-Dikic I, Gronroos E, Blaukat A et al. Pyk2 and FAK regulate neurite outgrowth induced by growth factors and integrins. Nat Cell Biol 2000; 2(9):574-581.

19. Turney SG, Bridgman PC. Laminin stimulates and guides axonal outgrowth via growth cone myosin II activity. Nat Neurosci 2005; 8(6):717-719.

20. Nakamoto T, Kain KH, Ginsberg MH. Neurobiology: New connections between integrins and axon guidance. Curr Biol 2004; 14(3):R121-R123.

21. Pasterkamp RJ, Peschon JJ, Spriggs MK et al. Semaphorin 7A promotes axon outgrowth through integrins and MAPKs. Nature 2003; 424(6947):398-405.

22. Julien F, Bechara A, Fiore R et al. Dual functional activity of semaphorin 3B is required for positioning the anterior commissure. Neuron 2005; 48(1):63-75.

23. Matthes DJ, Sink H, Kolodkin AL et al. Semaphorin II can function as a selective inhibitor of specific synaptic arborizations. Cell 1995; 81(4):631-639.

24. Liu XB, Low LK, Jones EG et al. Stereotyped axon pruning via plexin signaling is associated with synaptic complex elimination in the hippocampus. J Neurosci 2005; 25(40):9124-9134.

25. Marin O, Yaron A, Bagri A et al. Sorting of striatal and cortical interneurons regulated by semaphorin-neuropilin interactions. Science 2001; 293(5531):872-875.

26. Tamamaki N, Nakamura K, Kaneko T. Cell migration from the corticostriatal angle to the basal telencephalon in rat embryos. Neuroreport 2001; 12(4):775-780.

27. Kerjan G, Dolan J, Haumaitre C et al. The transmembrane semaphorin Sema6A controls cerebellar granule cell migration. Nat Neurosci 2005; 8(11):1516-1524.

28. Eickholt BJ, Mackenzie SL, Graham A et al. Evidence for collapsin-1 functioning in the control of neural crest migration in both trunk and hindbrain regions. Development 1999; 126(10):2181-2189.

29. Osborne NJ, Begbie J, Chilton JK et al. Semaphorin/neuropilin signaling influences the positioning of migratory neural crest cells within the hindbrain region of the chick. Dev Dyn 2005; 232(4):939-949.

30. Kawasaki T, Bekku Y, Suto F et al. Requirement of neuropilin 1-mediated Sema3A signals in patterning of the sympathetic nervous system. Development 2002; 129(3):671-680.

31. Gammill LS, Gonzalez C, Gu C et al. Guidance of trunk neural crest migration requires neuropilin 2/semaphorin 3F signaling. Development 2005.

32. Yu HH, Moens CB. Semaphorin signaling guides cranial neural crest cell migration in zebrafish. Dev Biol 2005; 280(2):373-385.

33. Brown CB, Feiner L, Lu MM et al. PlexinA2 and semaphorin signaling during cardiac neural crest development. Development 2001; 128(16):3071-3080. 
34. Feiner L, Webber AL, Brown CB et al. Targeted disruption of semaphorin 3C leads to persistent truncus arteriosus and aortic arch interruption. Development 2001; 128(16):3061-3070.

35. Cohen RI, Rottkamp DM, Maric D et al. A role for semaphorins and neuropilins in oligodendrocyte guidance. J Neurochem 2003; 85(5):1262-1278.

36. Spassky N, de Castro F, Le Bras B et al. Directional guidance of oligodendroglial migration by class 3 semaphorins and netrin-1. J Neurosci 2002; 22(14):5992-6004.

37. Goldberg JL, Vargas ME, Wang JT et al. An oligodendrocyte lineage-specific semaphorin, Sema5A, inhibits axon growth by retinal ganglion cells. J Neurosci 2004; 24(21):4989-4999.

38. Moreau-Fauvarque C, Kumanogoh A, Camand E et al. The transmembrane semaphorin Sema4D/ $\mathrm{CD} 100$, an inhibitor of axonal growth, is expressed on oligodendrocytes and upregulated after CNS lesion. J Neurosci 2003; 23(27):9229-9239.

39. Neufeld G, Lange T, Varshavsky A, Kessler O. Semaphorin signaling in vascular and tumor biology. In: Pasterkamp RJ, ed. Semaphorins: Receptor and Intracellular Signaling Mechanisms. Georgetown: Landes Bioscience, 2006.

40. Miao HQ, Soker S, Feiner L et al. Neuropilin-1 mediates collapsin-1/semaphorin III inhibition of endothelial cell motility: functional competition of collapsin- 1 and vascular endothelial growth factor-165. J Cell Biol 1999; 146(1):233-242.

41. Gu C, Yoshida Y, Livet J et al. Semaphorin 3E and plexin-D1 control vascular pattern independently of neuropilins. Science 2005; 307(5707):265-268.

42. Kessler O, Shraga-Heled N, Lange T et al. Semaphorin-3F is an inhibitor of tumor angiogenesis. Cancer Res 2004; 64(3):1008-1015.

43. Bielenberg DR, Hida Y, Shimizu A et al. Semaphorin $3 \mathrm{~F}$, a chemorepulsant for endothelial cells, induces a poorly vascularized, encapsulated, nonmetastatic tumor phenotype. J Clin Invest 2004; 114(9):1260-1271.

44. Dhanabal M, Wu F, Alvarez E et al. Recombinant Semaphorin 6A-1 Ectodomain Inhibits In Vivo Growth Factor and Tumor Cell Line-Induced Angiogenesis. Cancer Biol Ther 2005; 4(6):659-668.

45. Basile JR, Barac A, Zhu T et al. Class IV semaphorins promote angiogenesis by stimulating Rho-initiated pathways through plexin-B. Cancer Res 2004; 64(15):5212-5224.

46. Conrotto P, Valdembri D, Corso S et al. Sema4D induces angiogenesis through Met recruitment by Plexin B1. Blood 2005; 105(11):4321-4329.

47. Behar O, Golden JA, Mashimo H et al. Semaphorin III is needed for normal patterning and growth of nerves, bones and heart. Nature 1996; 383(6600):525-528.

48. Toyofuku T, Zhang H, Kumanogoh A et al. Dual roles of Sema6D in cardiac morphogenesis through region-specific association of its receptor, Plexin-A1, with off-track and vascular endothelial growth factor receptor type 2. Genes Dev 2004; 18(4):435-447.

49. Kikutani H. Semaphorin signalling during cardiac development. In: Pasterkamp RJ, ed. Semaphorins: Receptor and Intracellular Signaling Mechanisms. Georgetown: Landes Bioscience, 2006.

50. Ito T, Kagoshima M, Sasaki Y et al. Repulsive axon guidance molecule Sema3A inhibits branching morphogenesis of fetal mouse lung. Mech Dev 2000; 97(1-2):35-45.

51. Kagoshima M, Ito T. Diverse gene expression and function of semaphorins in developing lung: positive and negative regulatory roles of semaphorins in lung branching morphogenesis. Genes Cells 2001; 6(6):559-571.

52. Roy PJ, Zheng H, Warren CE et al. mab-20 encodes Semaphorin-2a and is required to prevent ectopic cell contacts during epidermal morphogenesis in Caenorhabditis elegans. Development 2000 Feb ;127 (4 ):755 -67 2000; 127(4):755-767.

53. Ginzburg VE, Roy PJ, Culotti JG. Semaphorin 1a and semaphorin $1 \mathrm{~b}$ are required for correct epidermal cell positioning and adhesion during morphogenesis in C. elegans. Development 2002; 129(9):2065-2078.

54. Fujii T, Nakao F, Shibata Y et al. Caenorhabditis elegans PlexinA, PLX-1, interacts with transmembrane semaphorins and regulates epidermal morphogenesis. Development 2002; 129(9):2053-2063.

55. Liu Z, Fujii T, Nukazuka A et al. C. elegans PlexinA PLX-1 mediates a cell contact-dependent stop signal in vulval precursor cells. Dev Biol 2005; 282(1):138-151.

56. Dalpe G, Brown L, Culotti JG. Vulva morphogenesis involves attraction of plexin 1-expressing primordial vulva cells to semaphorin 1a sequentially expressed at the vulva midline. Development 2005; 132(6):1387-1400.

57. Holmes S, Downs AM, Fosberry A et al. Sema7A is a potent monocyte stimulator. Scand J Immunol 2002; 56(3):270-275.

58. Chabbert-de Ponnat I, Marie-Cardine A, Pasterkamp RJ et al. Soluble CD100 functions on human monocytes and immature dendritic cells require plexin $\mathrm{C} 1$ and plexin $\mathrm{B} 1$, respectively. Int Immunol 2005; 17(4):439-447. 
59. Walzer T, Galibert L, De Smedt T. Dendritic cell function in mice lacking Plexin C1. Int Immunol 2005; 17(7):943-950.

60. Shi W, Kumanogoh A, Watanabe C et al. The class IV semaphorin CD100 plays nonredundant roles in the immune system: defective $\mathrm{B}$ and $\mathrm{T}$ cell activation in $\mathrm{CD} 100$-deficient mice. Immunity 2000; 13(5):633-642.

61. Kumanogoh A, Shikina T, Suzuki K et al. Nonredundant roles of Sema4A in the immune system: defective $\mathrm{T}$ cell priming and Th1/Th2 regulation in Sema4A-deficient mice. Immunity 2005; 22(3):305-316.

62. Wong AW, Brickey WJ, Taxman DJ et al. CIITA-regulated plexin-A1 affects T-cell-dendritic cell interactions. Nat Immunol 2003; 4(9):891-898.

63. Potiron V, Nasarre P, Roche J, Healy C, Boumsell L. Semaphorin signaling in the immune system. In: Pasterkamp RJ, ed. Semaphorins: Receptor and Intracellular Signaling Mechanisms. Georgetown: Landes Bioscience, 2006.

64. Christensen CR, Klingelhofer J, Tarabykina $S$ et al. Transcription of a novel mouse semaphorin gene, M-semaH, correlates with the metastatic ability of mouse tumor cell lines. Cancer Res 1998; 58(6): 1238-1244.

65. Kuroki T, Trapasso F, Yendamuri $S$ et al. Allelic loss on chromosome $3 \mathrm{p} 21.3$ and promoter hypermethylation of semaphorin 3B in non-small cell lung cancer. Cancer Res 2003; 63(12):3352-3355.

66. Miao HQ, Lee P, Lin $\mathrm{H}$ et al. Neuropilin-1 expression by tumor cells promotes tumor angiogenesis and progression. FASEB J 2000; 14(15):2532-2539.

67. Christensen C, Ambartsumian N, Gilestro G et al. Proteolytic processing converts the repelling signal Sema3E into an inducer of invasive growth and lung metastasis. Cancer Res 2005; 65(14):6167-6177.

68. Barberis D, Artigiani S, Casazza A et al. Plexin signaling hampers integrin-based adhesion, leading to Rho-kinase independent cell rounding, and inhibiting lamellipodia extension and cell motility. FASEB J 2004; 18(3):592-594.

69. Conrotto P, Corso S, Gamberini S et al. Interplay between scatter factor receptors and B plexins controls invasive growth. Oncogene 2004; 23(30):5131-5137.

70. Giordano S, Corso S, Conrotto P et al. The semaphorin $4 \mathrm{D}$ receptor controls invasive growth by coupling with Met. Nat Cell Biol 2002; 4(9):720-724.

71. Kusy S, Nasarre P, Chan D et al. Selective suppression of in vivo tumorigenicity by semaphorin SEMA3F in lung cancer cells. Neoplasia 2005; 7(5):457-465.

72. Maestrini E, Tamagnone T, Longati $\mathrm{P}$ et al. A family of transmembrane proteins with homology to the MET-hepatocyte growth factor receptor. Proc Natl Acad Sci USA 1996; 93:674-678.

73. Rohm B, Rahim B, Kleiber B et al. The semaphorin 3A receptor may directly regulate the activity of small GTPases. FEBS Lett 2000; 486(1):68-72.

74. Pasterkamp RJ, Kolodkin AL. Semaphorin junction: making tracks toward neural connectivity. Curr Opin Neurobiol 2003; 13(1):79-89.

75. Puschel AW. GTPases in semaphorin signalling. In: Pasterkamp RJ, ed. Semaphorins: Receptor and Intracellular Signaling Mechanisms. Georgetown: Landes Bioscience, 2006.

76. Driessens $\mathrm{MH}, \mathrm{Hu} \mathrm{H}$, Nobes $\mathrm{CD}$ et al. Plexin-B semaphorin receptors interact directly with active Rac and regulate the actin cytoskeleton by activating Rho. Curr Biol 2001; 11(5):339-344.

77. Vikis HG, Li W, He Z et al. The semaphorin receptor plexin-B1 specifically interacts with active Rac in a ligand-dependent manner. Proc Natl Acad Sci USA 2000; 97(23):12457-12462.

78. Turner LJ, Nicholls S, Hall A. The activity of the plexin-A1 receptor is regulated by Rac. J Biol Chem 2004; 279(32):33199-33205.

79. Jin Z, Strittmatter SM. Rac1 mediates collapsin-1-induced growth cone collapse. J Neurosci 1997; 17(16):6256-6263.

80. Kuhn TB, Brown MD, Wilcox CL et al. Myelin and collapsin-1 induce motor neuron growth cone collapse through different pathways: inhibition of collapse by opposing mutants of rac1. J Neurosci 1999; 19(6):1965-1975.

81. Vastrik I, Eickholt BJ, Walsh FS et al. Sema3A-induced growth-cone collapse is mediated by Rac1 amino acids 17- 32. Curr Biol 1999; 9(18):991-998.

82. Jurney WM, Gallo G, Letourneau PC et al. Rac1-mediated endocytosis during ephrin-A2- and semaphorin 3A-induced growth cone collapse. J Neurosci 2002; 22(14):6019-6028.

83. Hu H, Marton TF, Goodman CS. Plexin B mediates axon guidance in Drosophila by simultaneously inhibiting active Rac and enhancing RhoA signaling. Neuron 2001; 32(1):39-51.

84. Vikis HG, Li W, Guan KL. The plexin-B1/Rac interaction inhibits PAK activation and enhances Sema4D ligand binding. Genes Dev 2002; 16(7):836-845. 
85. Artigiani S, Barberis D, Fazzari P et al. Functional regulation of semaphorin receptors by proprotein convertases. J Biol Chem 2003; 278(12):10094-10101.

86. Zanata SM, Hovatta I, Rohm B et al. Antagonistic effects of Rnd1 and RhoD GTPases regulate receptor activity in Semaphorin 3A-induced cytoskeletal collapse. J Neurosci 2002; 22(2):471-477.

87. Oinuma I, Katoh H, Harada A et al. Direct interaction of Rnd 1 with Plexin-B1 regulates PDZ-RhoGEF-mediated Rho activation by Plexin-B1 and induces cell contraction in COS-7 cells. J Biol Chem 2003; 278(28):25671-25677.

88. Castellani V, De Angelis E, Kenwrick S et al. Cis and trans interactions of L1 with neuropilin-1 control axonal responses to semaphorin 3A. EMBO J 2002; 21(23):6348-6357.

89. Kantor DB, Chivatakarn O, Peer KL et al. Semaphorin $5 \mathrm{~A}$ is a bifunctional axon guidance cue regulated by heparan and chondroitin sulfate proteoglycans. Neuron 2004; 44(6):961-975.

90. Song H, Ming G, He Z et al. Conversion of neuronal growth cone responses from repulsion to attraction by cyclic nucleotides [see comments]. Science 1998; 281(5382):1515-1518.

91. Basile JR, Afkhami T, Gutkind JS. Semaphorin 4D/plexin-B1 induces endothelial cell migration through the activation of PYK2, Src, and the phosphatidylinositol 3-kinase-Akt pathway. Mol Cell Biol 2005; 25(16):6889-6898.

92. Zhang Z, Vuori K, Wang H et al. Integrin activation by R-ras. Cell 1996; 85(1):61-69.

93. Wozniak MA, Kwong L, Chodniewicz D et al. R-Ras controls membrane protrusion and cell migration through the spatial regulation of Rac and Rho. Mol Biol Cell 2005; 16(1):84-96.

94. Kinbara K, Goldfinger LE, Hansen M et al. Ras GTPases: integrins' friends or foes? Nat Rev Mol Cell Biol 2003; 4(10):767-776.

95. Marte BM, Rodriguez-Viciana P, Wennstrom S et al. R-Ras can activate the phosphoinositide 3-kinase but not the MAP kinase arm of the Ras effector pathways. Curr Biol 1997; 7(1):63-70.

96. Berrier AL, Mastrangelo AM, Downward J et al. Activated R-ras, Rac1, PI 3-kinase and PKCepsilon can each restore cell spreading inhibited by isolated integrin betal cytoplasmic domains. J Cell Biol 2000; 151(7):1549-1560.

97. Jeong HW, Nam JO, Kim IS. The COOH-terminal end of R-Ras alters the motility and morphology of breast epithelial cells through Rho/Rho-kinase. Cancer Res 2005; 65(2):507-515.

98. Arthur WT, Burridge K. RhoA inactivation by p190RhoGAP regulates cell spreading and migration by promoting membrane protrusion and polarity. Mol Biol Cell 2001; 12(9):2711-2720.

99. Barberis D, Casazza A, Sordella R et al. p190 Rho-GTPase activating protein associates with plexins and it is required for semaphorin signalling. J Cell Sci 2005; 118(Pt 20):4689-4700.

100. Ridley AJ, Hall A. The small GTP-binding protein rho regulates the assembly of focal adhesions and actin stress fibers in response to growth factors. Cell 1992; 70(3):389-399.

101. Raftopoulou M, Hall A. Cell migration: Rho GTPases lead the way. Dev Biol 2004; 265(1):23-32.

102. Komatsu M, Ruoslahti E. R-Ras is a global regulator of vascular regeneration that suppresses intimal hyperplasia and tumor angiogenesis. Nat Med 2005.

103. Driessens $\mathrm{MH}$, Olivo $\mathrm{C}$, Nagata $\mathrm{K}$ et al. B plexins activate Rho through PDZ-RhoGEF. FEBS Lett 2002; 529(2-3):168-172.

104. Hirotani M, Ohoka Y, Yamamoto T et al. Interaction of plexin-B1 with PDZ domain-containing Rho guanine nucleotide exchange factors. Biochem Biophys Res Commun 2002; 297(1):32-37.

105. Perrot V, Vazquez-Prado J, Gutkind JS. Plexin B Regulates Rho through the Guanine Nucleotide Exchange Factors Leukemia-associated Rho GEF (LARG) and PDZ-RhoGEF. J Biol Chem 2002; 277(45):43115-43120.

106. Swiercz JM, Kuner R, Behrens J et al. Plexin-B1 directly interacts with PDZ-RhoGEF/LARG to regulate RhoA and growth cone morphology. Neuron 2002; 35(1):51-63.

107. Aurandt J, Vikis HG, Gutkind IS et al. The semaphorin receptor plexin-B1 signals through a direct interaction with the Rho-specific nucleotide exchange factor, LARG. Proc Natl Acad Sci USA 2002; 99(19):12085-12090.

108. Swiercz JM, Kuner R, Offermanns S. Plexin-B1/RhoGEF-mediated RhoA activation involves the receptor tyrosine kinase ErbB-2. J Cell Biol 2004; 165(6):869-880.

109. Banerjee J, Wedegaertner PB. Identification of a novel sequence in PDZ-RhoGEF that mediates interaction with the actin cytoskeleton. Mol Biol Cell 2004; 15(4):1760-1775.

110. Toyofuku T, Yoshida J, Sugimoto T et al. FARP2 triggers signals for Sema3A-mediated axonal repulsion. Nat Neurosci 2005.

111. van Horck FP, Lavazais E, Eickholt BJ et al. Essential role of type I(alpha) phosphatidylinositol 4-phosphate 5-kinase in neurite remodeling. Curr Biol 2002; 12(3):241-245.

112. Eickholt BJ. Protein kinases in semaphorin signalling. In: Pasterkamp RJ, ed. Semaphorins: Receptor and Intracellular Signaling Mechanisms. Georgetown: Landes Bioscience, 2006.

113. Artigiani S, Conrotto P, Fazzari P et al. Plexin-B3 is a functional receptor for semaphorin 5A. EMBO Rep 2004; 5(7):710-714. 
114. Winberg ML, Tamagnone L, Bai J et al. The transmembrane protein Off-track associates with Plexins and functions downstream of Semaphorin signaling during axon guidance. Neuron 2001; 32(1):53-62.

115. Atwal JK, Singh KK, Tessier-Lavigne M et al. Semaphorin 3F antagonizes neurotrophin-induced phosphatidylinositol 3-kinase and mitogen-activated protein kinase kinase signaling: a mechanism for growth cone collapse. J Neurosci 2003; 23(20):7602-7609.

116. Takagi S, Kasuya Y, Shimizu M et al. Expression of a cell adhesion molecule, neuropilin, in the developing chick nervous system. Dev Biol 1995; 170(1):207-222.

117. Ohta K, Mizutani A, Kawakami A et al. Plexin: a novel neuronal cell surface molecule that mediates cell adhesion via a homophilic binding mechanism in the presence of calcium ions. Neuron 1995; 14(6):1189-1199.

118. Hartwig C, Veske A, Krejcova S et al. Plexin B3 promotes neurite outgrowth, interacts homophilically, and interacts with Rin. BMC Neurosci 2005; 6:53.

119. Shimizu M, Murakami Y, Suto F et al. Determination of cell adhesion sites of neuropilin-1. J Cell Biol 2000; 148(6):1283-1293.

120. Carmeliet P, Tessier-Lavigne M. Common mechanisms of nerve and blood vessel wiring. Nature 2005; 436(7048):193-200.

121. Kurschat P, Bielenberg D, Rossignol $M$ et al. Neuron restrictive silencer factor NRSF/REST is a transcriptional repressor of neuropilin-1 and diminishes the ability of semaphorin $3 \mathrm{~A}$ to inhibit keratinocyte migration. J Biol Chem 2005; 281(5):2721-2729.

122. Mikule K, Gatlin JC, de la Houssaye BA et al. Growth cone collapse induced by semaphorin 3A requires 12/15-lipoxygenase. J Neurosci 2002; 22(12):4932-4941.

123. Kashiwagi $\mathrm{H}$, Shiraga M, Kato $\mathrm{H}$ et al. Negative regulation of platelet function by a secreted cell repulsive protein, semaphorin 3A. Blood 2005; 106(3):913-921.

124. Delaire S, Billard C, Tordjman R et al. Biological activity of soluble CD100. II. Soluble CD100, similarly to H-SemaIII, inhibits immune cell migration. J Immunol 2001; 166(7):4348-4354.

125. Bachelder RE, Lipscomb EA, Lin X et al. Competing autocrine pathways involving alternative neuropilin-1 ligands regulate chemotaxis of carcinoma cells. Cancer Res 2003; 63(17):5230-5233.

126. Nasarre P, Constantin B, Rouhaud L et al. Semaphorin SEMA3F and VEGF have opposing effects on cell attachment and spreading. Neoplasia 2003; 5(1):83-92.

127. Nasarre P, Kusy S, Constantin B et al. Semaphorin SEMA3F has a repulsing activity on breast cancer cells and inhibits E-cadherin-mediated cell adhesion. Neoplasia 2005; 7(2):180-189.

128. Delorme G, Saltel F, Bonnelye E et al. Expression and function of semaphorin 7A in bone cells. Biol Cell 2005; 97(7):589-597.

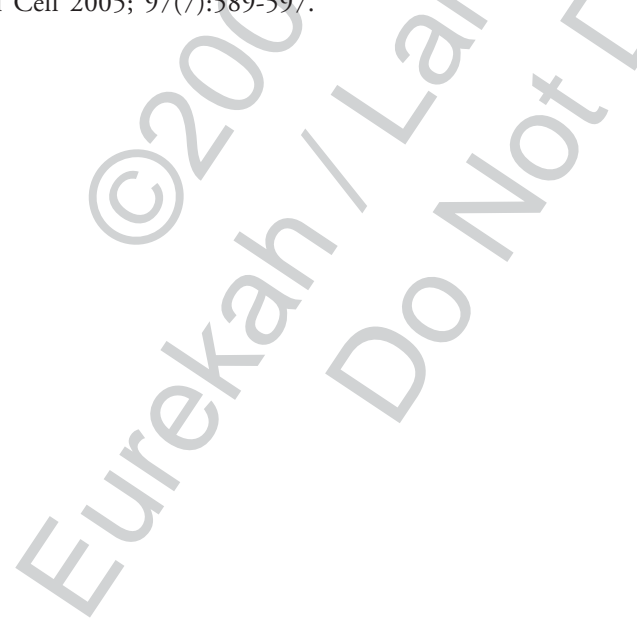

